\title{
Impact of pathologic body composition assessed by CT-based anthropometric measurements in adult patients with multiple trauma: a retrospective analysis
}

\author{
Balázs Poros ${ }^{1} \cdot$ Thomas Irlbeck $^{1} \cdot$ Philipp Probst $^{2} \cdot$ Alexander Volkmann $^{2} \cdot$ Philipp Paprottka $^{3} \cdot$ Wolfgang Böcker $^{4}$. \\ Michael Irlbeck ${ }^{1} \cdot$ Thomas Weig $^{1}$
}

Received: 12 August 2019 / Accepted: 11 November 2019 / Published online: 19 November 2019

(c) Springer-Verlag GmbH Germany, part of Springer Nature 2019

\begin{abstract}
Purpose In recent years, there has been mounting evidence on the clinical importance of body composition, particularly obesity and sarcopenia, in various patient populations. However, the relevance of these pathologic conditions remains controversial, especially in the field of traumatology. Computed tomography-based measurements allow clinicians to gain a prompt and thorough assessment of fat and muscle compartments in trauma patients. Our aim was to investigate whether CT-based anthropometric parameters of fat and muscle tissues show correlations with key elements of pre-hospital and clinical care in an adult population with multiple trauma.

Methods In this retrospective analysis we searched our institutional records of the German Trauma Registry (TraumaRegister DGU $^{\circledR}$ ) from January 2008 to May 2014. Included were 297 adult trauma patients with multiple trauma who underwent a whole-body CT-scan on admission and were treated in an ICU. We measured anthropometric determinants of abdominal core muscle and adipose tissue using the digital imaging software OsiriX ${ }^{\mathrm{TM}}$. Multivariate linear and logistic regression analyses were conducted to unveil potential correlations.

Results None of the obesity-linked anthropometric parameters were associated with longer pre-hospital or initial ED treatment times. Obese patients were less frequently intubated at the site of the accident. Patients with increased abdominal fat tissue received on average lower volumes during fluid resuscitation in the pre-hospital phase but were not more often in shock on admission. During ED treatment, fluid resuscitation and transfusion volumes were not affected by abdominal fat tissue, although transfusion rates were higher in the obese. Furthermore, damage control surgeries took place less frequently in patients with increased abdominal fat tissue markers. Obesity parameters did not affect the prevalence of sepsis, although increased abdominal fat was associated with higher white blood cell counts on admission. Finally, there was no statistically significant correlation between sarcopenia or obesity markers and duration of mechanical ventilation, ICU length of stay or neurologic outcome.

Conclusion CT-based assessment of abdominal fat and muscle mass is a simple method in revealing pathologic body composition in trauma patients. Our study suggests that obesity influences pre-hospital and ED treatment and early immune response in multiple trauma. Nevertheless, we could not demonstrate any significant effect of abdominal fat and muscle tissue parameters on the course of treatment, in particular the duration of mechanical ventilation, ICU length of stay and neurologic outcome.
\end{abstract}

Keywords Obesity $\cdot$ Sarcopenia $\cdot$ Multiple trauma $\cdot$ Anthropometry

\begin{tabular}{|c|c|c|c|}
\hline \multicolumn{2}{|c|}{ Abbreviations } & CNS & Central nervous system \\
\hline AIS & Abbreviated injury scale & DGU & German Society for Trauma Surgery \\
\hline \multirow[t]{2}{*}{ BMI } & Body mass index & DICOM & $\begin{array}{l}\text { Digital Imaging and Communications in } \\
\text { Medicine }\end{array}$ \\
\hline & & ED & Emergency department \\
\hline \multirow{2}{*}{ 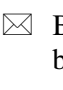 } & Poros & GCS & Glasgow Coma Scale \\
\hline & oros@med.uni-muenchen.de & GOS & Glasgow Outcome Scale \\
\hline \multicolumn{2}{|c|}{ Extended author information available on the last page of the article } & $\mathrm{RBC}$ & Red blood cell \\
\hline
\end{tabular}




$\begin{array}{ll}\text { SAD } & \text { Sagittal abdominal diameter } \\ \text { SBP } & \text { Systolic blood pressure } \\ \text { SAPS II } & \text { Simplified acute physiology score } \\ \text { SAT } & \text { Subcutaneous adipose tissue } \\ \text { SMI } & \text { Skeletal muscle index } \\ \text { SOFA } & \text { Sequential organ failure assessment } \\ \text { TMA } & \text { Total muscle area } \\ \text { VAT } & \text { Visceral adipose tissue } \\ \text { WBC } & \text { White blood cell }\end{array}$

\section{Introduction}

The effects of body composition on the clinical course in trauma patients have been subject to several studies in the past. These studies offered highly contradictory findings. A meta-analysis from 2013 implied that obesity had a negative effect on the mortality in trauma patients [1]. The publication of this meta-analysis triggered a controversy surrounding the impact of obesity on different subgroups of trauma patients, suggesting an "obesity-mortality" paradox in multiple trauma patients in ICUs. The negative correlation between obesity and mortality was no longer detectable in this subpopulation [2]. In past years, several studies have reported increased postoperative complications in obese patients after operative management of distal humeral, femoral shaft and ankle fractures [3-5]. On the contrary, Flodin et al. have found an increased 1-year survival and discharge to independent living in overweight $(\mathrm{BMI}>26)$ hip fracture patients [6].

The latter studies investigated patients with a single trauma, whereas little attention has been paid to the importance of body composition in severe multiple trauma. An observational prospective study found an increased risk of acute renal failure, infections, length of ICU stay, mean total hospital stay and duration of mechanical ventilation but no effects on multiple organ failure, pulmonary complications or mortality rate in patients with multiple trauma and BMI > 30 [7].

Although various techniques can be utilised to precisely assess body compartments (e.g., bioelectrical impedance and conductance methods, magnetic resonance imaging), the body mass index (BMI) is still the prevailing standard. However, BMI does not distinguish between muscle and fat tissues. Furthermore, weight and height are often unknown and remain unmeasured in ICU patients. Additionally, it has become evident that sarcopenia, a decrease in muscle mass and function, represents a pathologic condition of equal importance, especially in critically ill patients. So far, only a few studies have been published dealing specifically with the clinical impact of sarcopenia in trauma patients. Here again, the findings were controversial. Two retrospective studies have reported an association of sarcopenia, defined on the basis of the skeletal muscle index (cross-sectional muscle area at the L3 vertebra level divided by the square of height), with increased mortality. These studies have investigated elderly patients, predominantly with single fractures [8,9]. Moisey et al. have demonstrated in severely injured patients over 65 years of age a negative impact of sarcopenia, assessed by computed tomography analysis with regards to ICU-free and ventilator-free days [10]. In this population, there was no correlation between the above-mentioned clinical end-points and BMI. On the other hand, a more recent study has found no association between sarcopenia and complications or mortality in geriatric trauma patients [11]. Due to the increasing availability of computed tomography scans, new CT-based definitions of the aforementioned pathological conditions have been published, making their standardised investigation and comparison possible [12-16].

The aim of the present study is to determine whether a correlation exists between CT-based anthropometric markers of obesity or sarcopenia and key elements of the clinical course in patients of all ages with severe multiple trauma. As these pathological conditions can be promptly assessed by analysing the initial CT-scan using an easy-to-learn algorithm [17], this approach could provide invaluable additional information in risk stratification and help us better understand the role of pathologic body composition in trauma.

\section{Patients and methods}

\section{Patients and data collection}

This retrospective study was conducted at the University Hospital of Munich (LMU), Germany, a level-I regional adult trauma centre. We analysed local records of the Trauma Registry belonging to the German Society for Trauma Surgery (TraumaRegister DGU ${ }^{\circledR}$ ) from January 2008 to May 2014. Included were patients who underwent whole-body cross-sectional CT-scanning on admission after severe multiple trauma. This was defined on the basis of the abbreviated injury scale (AIS): patients were included if they had injuries involving at least two body regions with at least one moderate injury (AIS $\geq 2$ ) and were admitted to an ICU after initial assessment or surgery.

\section{Imaging technique}

A 256-slice dual-source whole-body CT scan in the supine position was performed on admission. The initial scan consisted of a non-contrast head scan followed by the injection of $120 \mathrm{~mL}$ contrast agent (Imeron 350; Bracco SpA, Milan, Italy) and acquisition of an arterial phase scan including head, neck, thorax, and abdomen, as well as a venous phase scan including abdomen and the lower extremities where indicated. We analysed the venous abdomen scans in this 
study (120 kV/pitch $1.5 \mathrm{~mm}$; 5- and 1-mm reconstructions) (Fig. 1).

\section{Imaging analysis}

All CT-scans were analysed using the DICOM software OsiriX ${ }^{\mathrm{TM}}$ (OsiriX Lite, Pixmeo, Geneva, Switzerland). Two independent investigators analysed the images using the method described by Irlbeck et al. [17] Intra- and interobserver reliabilities were high with an intraclass correlation coefficient greater than 0.95 . After localising the inferior posterior border of the third vertebral body, anthropometric indices were measured using a Hounsfield unit range from -30 to $+150 \mathrm{HU}$ for lean muscle tissue and from -195 to $-45 \mathrm{HU}$ for fat tissue. We then obtained the following abdominal fat tissue parameters: Sagittal abdominal diameter (SAD), subcutaneous fat tissue (SAT), and visceral fat tissue (VAT). Total muscle area (TMA) was measured to quantify muscle tissue (Fig. 1). $\mathrm{SAD}$ is expressed in $\mathrm{cm}$, all other parameters in $\mathrm{cm}^{2}$. For the purpose of anthropometric characterisation of the study group we used the following definitions:

Central obesity: $\mathrm{SAD} \geq 26 \mathrm{~cm}$ [18] and gender-specific, VAT-based cutoff values (male: $>131 \mathrm{~cm}^{2}$; female: $>110$ $\left.\mathrm{cm}^{2}\right)[13,19]$

Sarcopenia: TMA male $:<170 \mathrm{~cm}^{2}, \mathrm{TMA}_{\text {female }}<110 \mathrm{~cm}^{2}$ $[14,15]$

\section{Study design}

The course of treatment was broken down into three parts: pre-hospital care, ED and ICU. In addition, patient outcome was measured using the Glasgow Outcome Scale.

We hypothesised that fat tissue parameters have significant effects on the key elements of the pre-hospital phase, in particular on the duration of treatment, intubation rate and fluid resuscitation.

Subsequently, the correlation between obesity and fluid resuscitation in the ED including transfusion of blood products (RBC, fresh frozen plasma, platelet concentrates) was analysed. We also searched for significant effects of obesity markers on the duration of first assessments and initial treatment in the ED, defined as the time interval between admission to the emergency room and the whole-body CT scan. Furthermore, we examined whether fat or muscle tissue parameters had an association with the risk of developing shock, defined as systolic blood pressure (SBP) lower than $90 \mathrm{mmHg}$ or heart rate-SBPratio greater than 1 or base excess less than $-6 \mathrm{mmol} / \mathrm{L}$. We then investigated whether obesity had an effect on the initial surgical procedure. Blood glucose level and white blood cell count on admission were also analysed to assess metabolic status and early inflammatory responses.

In the third part, we focused on the ICU treatment. We evaluated the relationship between sepsis (according to the 2001 International Sepsis Definitions Conference Criteria [20]) and body composition. Furthermore, correlations of

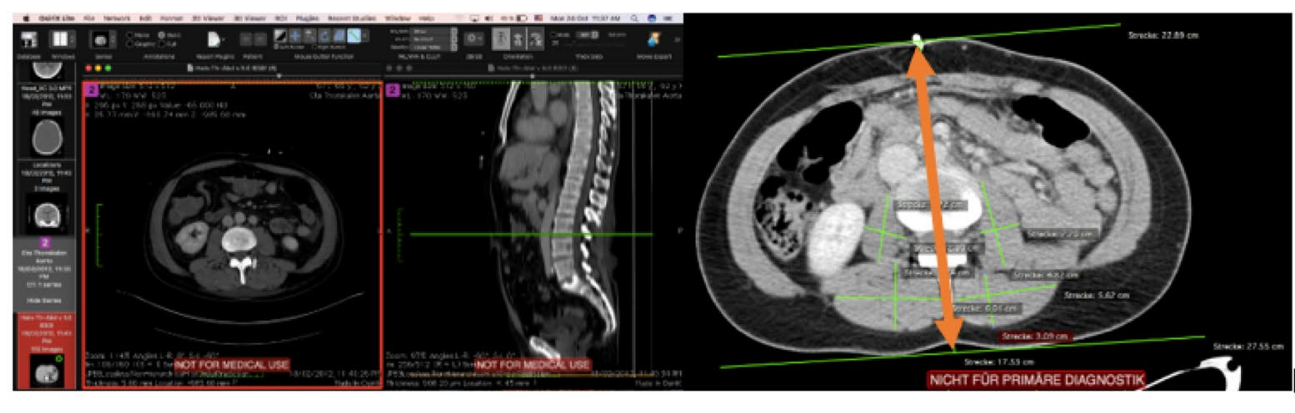

SAD

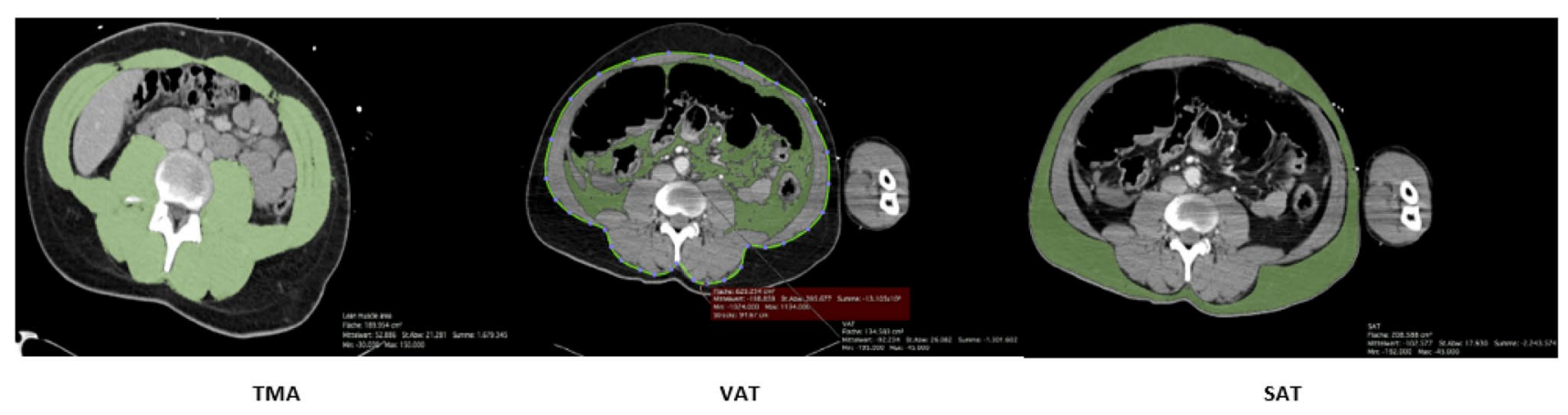

Fig. 1 Imaging analysis: measuring diametric (SAD) and planimetric parameters (TMA, VAT, SAT) of abdominal fat and muscle tissue at the level of the inferior posterior border of the L3 vertebra 
obesity and sarcopenia parameters and duration of mechanical ventilation as well as length of ICU stay were analysed. Finally, we tested whether there was a correlation between obesity/sarcopenia markers and the outcome as assessed by the Glasgow Outcome Scale $(1=$ death, $2=$ persistent vegetative state, $3=$ severe disability, $4=$ moderate disability, $5=$ low disability). Patients with severe brain or spinal injury (AIS head $>3$, AIS spine $>3$ ) were excluded from analyses of length of ICU stay, duration of mechanical ventilation and neurologic outcome.

\section{Statistical analysis}

For the demographic data, we computed mean and standard deviation for continuous variables, and median and interquartile range if outliers were present or if the distribution was heavily skewed. For discrete variables we calculated the absolute and relative frequencies. To measure the linear dependence between variables, we used linear models if the dependent variable was continuous and added other possible covariates. In case of duration or time variables (ventilation time, duration of intensive therapy), we used a log-transformation on the variables to fulfil the normality assumption. In case of binary dependent variables, we used logistic regression and included other possible covariates. Due to the exploratory nature of the study we did not correct the significance levels for multiple testing.

The variables of obesity (SAD/SAT/VAT/SAT + VAT) and muscle mass (TMA) were included as raw independent variables in the models to retain as much information as possible. For each of the variables, a model was fitted to compare the different influences of the fat parameters.

The variables corrected for in the multivariate analyses are included in each table. Taking gender into account as a confounder did not change the main results of the analysis and the variable in itself does not significantly alter any of the other analysed variables. To improve readability and model parsimony, we excluded gender from the analyses for pre-hospital and early ED treatment.

The data analysis was performed using the statistical software $\mathrm{R}$ version 3.6.0.

\section{Results}

297 patients met the inclusion criteria and were enrolled in the study. The study group consisted of 220 (74\%) male and $77(26 \%)$ female patients with a mean age of $45( \pm 20)$. The main causes of trauma were motor vehicle accidents $(N=197,66 \%)$ and falls $(N=87,29 \%) .243$ patients $(82 \%)$ had at least one injury with an AIS-Score $\geq 3.253$ patients $(85 \%)$ had injuries in at least 3 different body regions. Injury pattern and severity are shown in Table 1.

Mean SAPS II Score on admission to the ICU was 32 $( \pm 17)$. Median ICU stay was 4 days (IQR 9). 186 patients (63\%) received mechanical ventilation in the ICU with a median duration of 4.2 days (IQR 10). 69 patients (23\%) fulfilled the sepsis criteria. 30 patients $(10 \%)$ died during intensive care treatment. In 63 cases $(21 \%)$ neurologic outcome was poor (GOS 2-3) whereas 202 patients $(68 \%)$ had a GOSScore $\geq 4$ upon discharge corresponding to low or moderate disability. In 2 patients, neurologic outcome was not specified.

Anthropometric analysis of the study group showed that 53 patients (18\%) could be classified as centrally obese according to the SAD-based definition [18]. The application of VAT-based cutoff values resulted in a greater number of patients being classified as obese, with 81 male and 9 female trauma victims, a total of $90(30 \%)[13,19]$. Using the TMA-based threshold, 55 male and 14 female patients were classified as sarcopenic $(n=69,23 \%)[14,15]$.

Our analysis showed that elderly patients ( $\geq 65$ years) had significantly reduced core muscle (TMA being lower) whereas abdominal fat tissue was increased (higher SAT + VAT and $\mathrm{SAD}$ ), as shown in Fig. 2 in "Appendix" and Table 2.
Table 1 Injury patterns in the study group showing injury severity in each body region, based on the Abbreviated Injury Score $(1=$ Minor, $2=$ Moderate, $3=$ Serious, $4=$ Severe, $5=$ Critical, $6=$ Maximum) and the GCS

\begin{tabular}{lccccccc}
\hline & \multicolumn{1}{l}{ All } & \multicolumn{1}{l}{ Male } & Female & AGe $\geq 65$ & Obese & Sarcopenia & $P$ value \\
\hline Head & $1.8 \pm 1.7$ & $1.8 \pm 1.7$ & $2 \pm 1.8$ & $2.1 \pm 1.6$ & $1.4 \pm 1.4$ & $1 \pm 0$ & 0.022 \\
Face & $0.5 \pm 0.8$ & $0.5 \pm 0.8$ & $0.6 \pm 0.9$ & $0.4 \pm 0.8$ & $0.4 \pm 0.7$ & $0.8 \pm 0.4$ & 0.182 \\
Neck & $0.1 \pm 0.5$ & $0.1 \pm 0.6$ & $0.1 \pm 0.3$ & $0 \pm 0.3$ & $0.1 \pm 0.4$ & $0 \pm 0$ & 0.479 \\
Thorax & $2 \pm 1.5$ & $1.9 \pm 1.6$ & $2 \pm 1.5$ & $2 \pm 1.5$ & $2.2 \pm 1.4$ & $0.7 \pm 1.3$ & 0.503 \\
Abdomen & $0.7 \pm 1.3$ & $0.7 \pm 1.2$ & $1 \pm 1.5$ & $0.6 \pm 1.1$ & $0.6 \pm 1.1$ & $0 \pm 0$ & 0.893 \\
Spine & $1 \pm 1.4$ & $1.1 \pm 1.4$ & $0.7 \pm 1.2$ & $1 \pm 1.3$ & $1.2 \pm 1.4$ & $0.7 \pm 1.3$ & 0.158 \\
Upper extremity & $1 \pm 1$ & $1 \pm 1$ & $1 \pm 1$ & $0.9 \pm 1$ & $0,7 \pm 1$ & $1,5 \pm 0,8$ & 0.392 \\
Lower extremity & $1.6 \pm 1.5$ & $1.5 \pm 1.5$ & $1.6 \pm 1.5$ & $1.2 \pm 1.5$ & $1.3 \pm 1.5$ & $0 \pm 0$ & 0.869 \\
Other & $0 \pm 0.2$ & $0 \pm 0.2$ & $0 \pm 0$ & $0 \pm 0.1$ & $0 \pm 0.1$ & $0 \pm 0$ & 0.140 \\
AIS max & $3.5 \pm 1$ & $3.5 \pm 1$ & $3.4 \pm 1.1$ & $3.3 \pm 1$ & $3.3 \pm 0.9$ & $2.2 \pm 0.4$ & 0.850 \\
GCS crash site & $12.5 \pm 4$ & $12.5 \pm 4.1$ & $12.5 \pm 3.7$ & $12.3 \pm 3.9$ & $13.2 \pm 3.5$ & $15 \pm 0$ & 0.969 \\
\hline
\end{tabular}

In each case, mean and standard deviation are shown. $P$ values are calculated with a Wilcoxon-MannWhitney test between sarcopenic and non-sarcopenic patients 
Median duration of pre-hospital treatment in the study population was $68.5 \mathrm{~min}$ (IQR 47.5). A multivariate linear regression analysis showed no correlation between obesity markers and duration of pre-hospital treatment (Table 6 in "Appendix").

According to the results of the multivariate analysis shown in Table 3, obese patients were less likely to be intubated at the site of the accident regardless of whether we tested using diametric or planimetric markers.

As shown in the multivariate regression analyses in Tables 4 and 5, patients with increased total abdominal fat mass $(\mathrm{SAT}+\mathrm{VAT})$ received lower volumes of fluid resuscitation on the site of the accident. In contrast, there was no detectable effect of obesity on fluid resuscitation or transfusion volumes during early ED treatment. However, abdominal fat tissue parameters were positively correlated to the transfusion rate.

Further analyses showed that duration of initial treatment in the ED did not correlate with any of the fat tissue markers (Table 7 in "Appendix"). Neither abdominal fat tissue nor TMA showed a correlation with the risk of developing shock during pre-hospital or ED treatment (Table 8 in "Appendix").

We found that patients with less abdominal fat tissue (lower SAD and SAT + VAT) were more likely to undergo damage control surgery prior to admission to the ICU (Fig. 3 in "Appendix").

We found a significant positive correlation of baseline glucose level and obesity markers. Moreover, white blood cell count on admission was elevated in patients with higher fat tissue markers (Tables 9, 10 in "Appendix").

The multivariate logistic regression model shown in Table 11 in "Appendix" demonstrated no relationship between sepsis during intensive care therapy and the indices of abdominal fat or muscle tissue. As shown in Tables 12 and 13 in "Appendix", neither obesity nor sarcopenia parameters were associated with longer duration of mechanical ventilation or ICU therapy. On the other hand, head and thorax injury severity, higher maximum AIS and initial SAPS II scores were correlated with prolonged mechanical ventilation and ICU stay.

Finally, maximum AIS and initial SAPS II scores and poor neurologic outcome were positively correlated as seen in Table 14 in "Appendix" but none of the investigated anthropometric parameters showed a correlation with this end-point.

\section{Discussion}

The purpose of the current study was to investigate correlations of the clinical course and pathologic body composition in multiple trauma patients with the aid of a CT-based assessment of abdominal fat and muscle tissue. We found significant correlations between obesity markers and key elements of the pre-hospital and ED treatment, including intubation rate, fluid resuscitation, transfusion rate and the occurrence of damage control surgery. On the other hand, duration of the pre-hospital

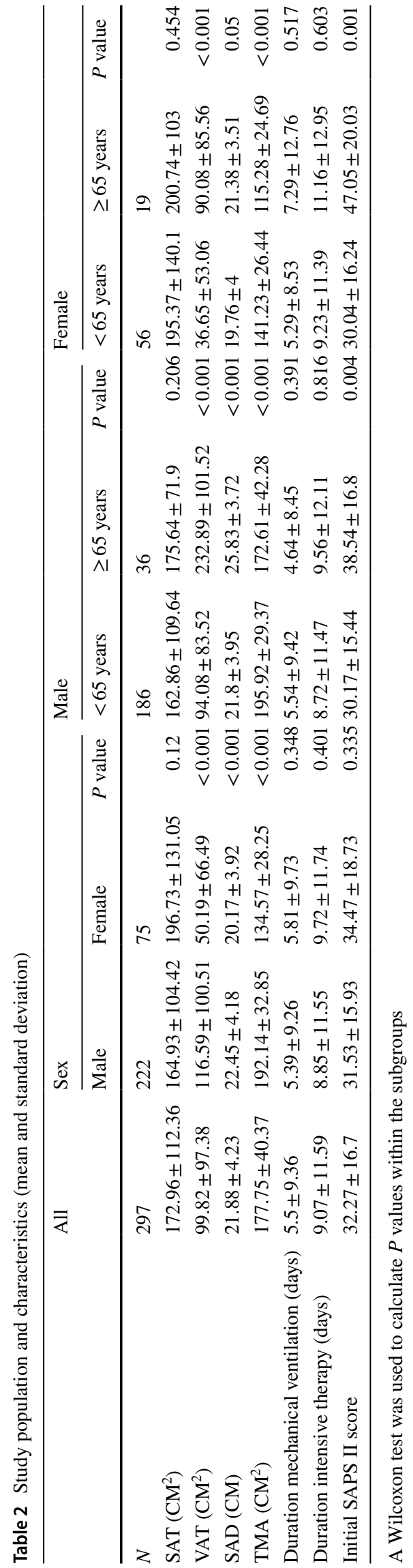


Table 3 Multivariate logistic regression model with the dependent variable intubation, including the confounding factors initial GCS, AIS head and thorax

\begin{tabular}{llclrr}
\hline Response & Independent variable & Odds ratio & $95 \%$ CI & $z$ value & $P$ value \\
\hline Intubation & SAD & 0.902 & {$[0.83,0.977]$} & -2.461 & 0.013 \\
& GCS $<8$ & 21.61 & {$[6.904,96.57]$} & 4.710 & $<0.001$ \\
& AIS head & 1.244 & {$[1.026,1.512]$} & 2.227 & 0.025 \\
& AIS thorax & 1.264 & {$[1.033,1.554]$} & 2.258 & 0.023 \\
Intubation & SAT & 0.996 & {$[0.993,1)$} & -2.051 & 0.040 \\
& GCS $<8$ & 20.71 & {$[6.688,91.557]$} & 4.689 & $<0.001$ \\
& AIS head & 1.264 & {$[1.045,1.533]$} & 2.410 & 0.015 \\
& AIS thorax & 1.245 & {$[1.02,1.529]$} & 2.136 & 0.015 \\
& VAT & 0.994 & {$[0.991,0.998]$} & -2.698 & 0.006 \\
& GCS $<8$ & 23.53 & {$[7.408,106.613]$} & 4.783 & $<0.001$ \\
& AIS head & 1.24 & {$[1.027,1.514]$} & 2.237 & 0.025 \\
& AIS thorax & 1.229 & {$[1.006,1.51]$} & 2.006 & 0.044 \\
& SAT + VAT & 0.997 & {$[0.995,0.999]$} & -2.745 & 0.006 \\
& GCS $<8$ & 22.54 & {$[7.152,101.211]$} & 4.752 & $<0.001$ \\
& AIS Head & 1.247 & {$[1.029,1.515]$} & 2.251 & 0.024 \\
& AIS thorax & 1.245 & {$[1.019,1.53]$} & 2.126 & 0.033 \\
\hline
\end{tabular}

Table 4 Multivariate linear regression models with the dependent variable fluid resuscitation (pre-hospital and ED), including the confounding variables AIS thorax/abdomen/lower extremities and primary intubation

\begin{tabular}{|c|c|c|c|c|c|}
\hline Response & Independent variable & Beta coefficient & $95 \% \mathrm{CI}$ & $T$ value & $P$ value \\
\hline \multirow[t]{5}{*}{ Fluid resuscitation (pre-hospital) } & $\mathrm{SAT}+\mathrm{VAT}$ & -0.702 & {$[-1.375,-0.031]$} & -2.062 & 0.040 \\
\hline & AIS thorax & 73.23 & {$[-7.318,153.78]$} & 1.791 & 0.074 \\
\hline & AIS abdomen & 12.02 & {$[-84.713,108.754]$} & 0.245 & 0.806 \\
\hline & AIS lower extremities & 33.82 & {$[-47.307,114.947]$} & 0.821 & 0.412 \\
\hline & Primary intubation & 1331.4 & {$[1077.029,1585.876]$} & 10.311 & $<0.001$ \\
\hline \multirow[t]{5}{*}{ Fluid resuscitation (ED) } & $\mathrm{SAT}+\mathrm{VAT}$ & -0.09264 & {$[-1.576,1.391]$} & -0.123 & 0.902 \\
\hline & AIS thorax & 99.65549 & {$[-76.906,276.217]$} & 1.111 & 0.267 \\
\hline & AIS abdomen & 219.66567 & {$[1.871,437.461]$} & 1.985 & 0.048 \\
\hline & AIS lower extremities & 430.54655 & {$[254.118,606.975]$} & 4.803 & $<0.001$ \\
\hline & Primary intubation & 653.32465 & {$[109.89,1196.759]$} & 2.366 & 0.018 \\
\hline
\end{tabular}

Table 5 Multivariate logistic regression model for the dependent variable transfusion rate and multivariate linear regression model for the dependent variable transfusion volume ( $\mathrm{RBC}$, fresh frozen plasma and thrombocyte concentrates), including the confounding variables AIS thorax/abdomen/lower extremities

\begin{tabular}{llrlrr}
\hline Response & Independent variable & Beta coefficient & 95\% CI & $T$ value & $P$ value \\
\hline Transfusion rate (ED) & SAT + VAT & -0.0018863 & {$[-0.004,0]$} & -1.962 & 0.049 \\
& AIS thorax & 0.2501986 & {$[0.044,0.463]$} & 2.353 & 0.0186 \\
& AIS abdomen & 0.4948687 & {$[0.272,0.726]$} & 4.285 & $<0.001$ \\
& AIS lower extremities & 0.4215653 & {$[0.217,0.638]$} & 3.941 & $<0.001$ \\
Transfusion volume (ED) & SAT + VAT & -0.0001956 & {$[-0.03,0.03]$} & -0.013 & 0.989 \\
& AIS thorax & 1.9159309 & {$[-1.415,5.247]$} & 1.148 & 0.255 \\
& AIS abdomen & 3.3491429 & {$[0.316,6.382]$} & 2.204 & 0.031 \\
& AIS lower extremities & 3.6543707 & {$[0.753,6.556]$} & 2.514 & 0.014 \\
\hline
\end{tabular}

and initial ED treatment phase or incidence of shock in the ED were not affected by pathologic body composition. None of the investigated indices had a statistically significant correlation with occurrence of sepsis during the clinical course although increased abdominal fat was associated with higher white blood cell counts on admission. Neither obesity nor sarcopenia parameters influenced the duration of mechanical ventilation, length of ICU stay or neurologic outcome.

The investigated cohort had a median age of 45 years, which distinguishes our study from most published data on 
this topic, where previous studies mainly reported on patients over 65 years of age. The dominance of the male gender in multiple trauma victims, as seen in our study population, has been described before [21]. We found a significant relationship between age and pathologic body composition. However, one must carefully note differences in assessments when quantifying the prevalence of central obesity: using a single planimetric measurement (SAD) or gender-specific cutoff values of planimetric markers (VAT). This discrepancy may be due to the different distribution of fat tissue, leading to a preferential accumulation of VAT in men and SAT in women [22, 23]. In 2013, the WHO reported that $25.1 \%$ of the adult population in Germany was obese. This is comparable to the prevalence of obesity in our study group, making a relevant selection bias unlikely [24]. The observed positive correlation of blood glucose level and fat mass corroborates the validity of the applied methodology in assessing abdominal adipose tissue and obesity.

Injury pattern and severity were independent of body composition except for head injuries, which were less severe in obese patients. This has been repeatedly demonstrated over the past decades despite the improvements in traffic safety [25-27].

Contrary to our expectations, the present study did not find any significant association between obesity parameters and duration of pre-hospital and initial ED treatment. It would be easy but likely misleading to conclude that all patients benefitted equally from a "scoop-and-run" concept during pre-hospital treatment, where rapid transport is prioritized. The median duration of pre-hospital treatment of 68.5 min appears, at first glance, surprisingly long. It is possible, especially after motor vehicle accidents, which account for $66 \%$ of all cases, that aggravating circumstances such as challenging rescue conditions prolonged the duration of pre-hospital treatment. In the emergency department, strictly regulated therapy algorithms ensure that virtually no delays occur due to pathologic body composition.

The inverse correlation of obesity parameters and intubation rate might be a reflection of the first responder's insecurity when confronted with an obese patient, as an association between obesity and difficult airways is well established [28, 29]. In addition, a dense healthcare network such as in the primary reference area of our study centre can occasionally allow postponement of a definitive airway until hospital admission.

We found that patients with increased abdominal fat tissue received less fluid substitution during pre-hospital treatment. A possible explanation for this may be the lack of adequate intravenous access due to difficult punctures in the obese population. Previous observations among burn victims have also shown that obesity was associated with restrictive fluid resuscitation [30, 31]. Another retrospective study has reported similar trends in trauma patients and an increased rate of hemorrhagic shock [32]. In contrast to this particular study, we did not detect any correlation between obesity parameters and shock on admission. This may be the reason why obesity did not influence fluid challenge and transfusion volumes during early ED treatment in our cohort. However, we observed a higher overall transfusion rate in the obese, which is consistent with findings of other studies [33, 34]. It is possible that a more liberal transfusion regime in the obese has a negative impact on the clinical course.

The observed inverse correlation between obesity and damage control surgery is in agreement with findings of an earlier prospective study in multiple trauma patients [7].

The most surprising finding was the lack of correlation between the clinical end-points and the anthropometric measurements. If sarcopenia and obesity clearly appear to increase morbidity in patients with single fractures, then why does this negative impact disappear in the case of severe injuries requiring intensive care? [2] One of the possible explanations might be the fat tissue-induced immunomodulation in this setting. It is known that adipose tissue plays an important role in early posttraumatic immune response, which is reflected by increased blood levels of IL-6 and CRP [27]. However, obese patients can have elevated baseline blood levels of inflammatory markers and white blood cell count without trauma, presumably due to a chronic inflammatory state [35]. This fact makes the interpretation of the laboratory alterations after severe trauma difficult without baseline comparison. We also observed a significant positive correlation between obesity parameters and initial white blood cell count which could be interpreted as a trauma-induced burst of the immune system. As shown in the corresponding multivariate analyses, injury severity and pattern have a fundamental impact on the duration of mechanical ventilation and ICU stay that could mask the effects caused by obesity and sarcopenia in severe multiple trauma.

A number of caveats need to be noted regarding the present study. First, pre-hospital data are known to be prone to considerable error due to time pressure and stress. Second, due to insufficient data collection, we were not able to compare CTbased measurements with traditional anthropometric indices such as BMI or waist-to-hip ratio. Further studies should take SMI into account as it may provide a more accurate identification of sarcopenia.

The prevalence of obesity-linked morbidities, such as surgical site infections or deep venous thrombosis could not be accounted for in the present study since the DGU registry does not supply this information. This also applies to some potentially biasing factors such as possibly more generous admission of obese patients to the ICU or nutrition regimes.

\section{Conclusion}

CT-based assessment of abdominal fat and muscle mass is a simple method to reveal pathologic body composition in trauma patients. We did not see an effect of obesity markers on the duration of pre-hospital or initial ED treatment in this population. We found a significant negative correlation 
of abdominal fat tissue parameters and pre-hospital intubation rate. Although patients with higher fat tissue parameters received less fluid resuscitation prior to admission, the rate of shock in the ED was not increased. During initial ED treatment, there was no detectable effect of obesity on fluid resuscitation or transfusion volumes although abdominal fat tissue parameters were positively correlated with the transfusion rate. Moreover, obese patients were less likely to undergo damage control surgery. None of the investigated anthropometric parameters had a statistically significant correlation with occurrence of sepsis during the clinical course. Neither obesity nor sarcopenia influenced duration of mechanical ventilation, length of ICU stay or neurologic outcome.

Acknowledgements The authors thank Anne Guo for comments that greatly improved the manuscript.

Author contributions According to the definitions outlined by the International Committee of Medical Journal Editors (ICMJE), the authors listed above qualify for authorship based on having made one or more substantial contributions to the intellectual content of the article: BP, TW, TI designed the study. BP, TI, WB, PPa acquired the data. BP, PPr, AV analysed and interpreted the data. BP, TW drafted the manuscript. All authors approved the final submitted version of the manuscript.

Funding None.

Data availability The datasets used and analysed during the current study are available from the corresponding author upon request.

\section{Compliance with ethical standards}

Conflict of interests The authors declare that they have no competing interests.

Ethics approval The present study was approved by the local institutional review board (UE no. 71-15).

Informed consent The requirement to obtain an informed consent form was waived.

\section{Appendix}

See Figs. 2, 3 and Tables 6, 7, 8, 9, 10, 11, 12, 13, 14.
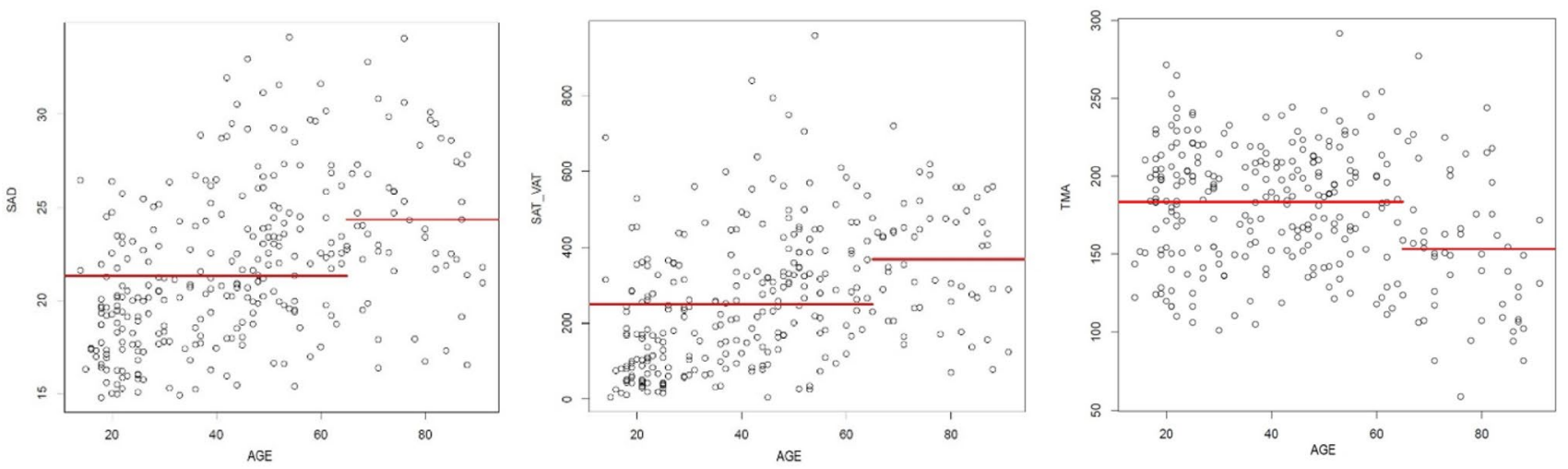

Fig. 2 Scatter plots showing the correlation between age (years), SAD (cm), SAT + VAT and TMA (cm2). The horizontal lines indicate the mean values in the subgroups

Fig. 3 Distribution of obesity parameters in patients with ("Yes") and without ("No") damage control surgery prior to admission to the ICU. Wilcoxon tests using the fat tissue parameters $\operatorname{SAD}(\mathrm{P}=0.01)$ and $\mathrm{SAT}+\mathrm{VAT}(\mathrm{P}=0.007)$
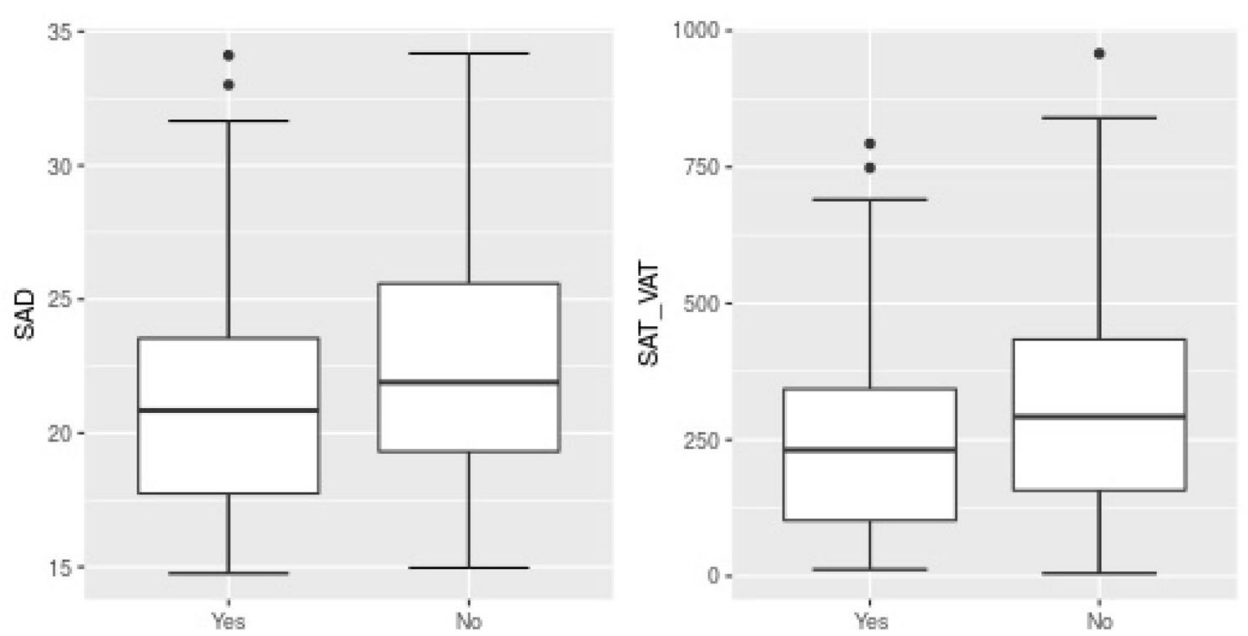
Table 6 Multivariate linear regression model with duration of pre-hospital treatment as independent variable

\begin{tabular}{|c|c|c|c|c|c|}
\hline Response & Independent variable & Beta coefficient & $95 \% \mathrm{CI}$ & $T$ value & $P$ value \\
\hline \multirow[t]{11}{*}{ Duration pre-hospital treatment } & SAD & 0.017 & {$[-0.005,0.04]$} & 1.563 & 0.119 \\
\hline & Type of accident 2 & 0.643 & {$[0.29,0.997]$} & 3.588 & $<0.001$ \\
\hline & Type of accident 3 & 0.672 & {$[0.28,1.065]$} & 3.378 & $<0.001$ \\
\hline & Type of accident 4 & 0.363 & {$[-0.11,0.836]$} & 1.513 & 0.131 \\
\hline & Type of accident 5 & 0.814 & {$[0.389,1.239]$} & 3.776 & $<0.001$ \\
\hline & Type of accident 6 & 0.559 & {$[0.182,0.938]$} & 2.920 & 0.003 \\
\hline & Type of accident 7 & 0.610 & {$[0.007,1.214]$} & 1.993 & 0.047 \\
\hline & AIS thorax & -0.015 & {$[-0.077,0.047]$} & -0.480 & 0.631 \\
\hline & AIS abdomen & 0.023 & {$[-0.052,0.099]$} & 0.610 & 0.542 \\
\hline & AIS lower extremities & 0.005 & {$[-0.06,0.071]$} & 0.165 & 0.869 \\
\hline & Primary intubation & 0.407 & {$[0.212,0.603]$} & 4.117 & $<0.001$ \\
\hline \multirow[t]{11}{*}{ Duration pre-hospital treatment } & SAT & 0.0004 & {$[0,0.001]$} & 1.156 & 0.248 \\
\hline & Type of accident 2 & 0.651 & {$[0.297,1.006]$} & 3.622 & $<0.001$ \\
\hline & Type of accident 3 & 0.685 & {$[0.29,1.081]$} & 3.420 & $<0.001$ \\
\hline & Type of accident 4 & 0.358 & {$[-0.116,0.833]$} & 1.489 & 0.138 \\
\hline & Type of accident 5 & 0.875 & {$[0.456,1.295]$} & 4.116 & $<0.001$ \\
\hline & Type of accident 6 & 0.585 & {$[0.208,0.962]$} & 3.057 & 0.002 \\
\hline & Type of accident 7 & 0.653 & {$[0.044,1.263]$} & 2.112 & 0.035 \\
\hline & AIS thorax & -0.011 & {$[-0.073,0.05]$} & -0.364 & 0.716 \\
\hline & AIS_abdomen & 0.026 & {$[-0.05,0.102]$} & 0.676 & 0.499 \\
\hline & AIS lower extremities & 0.004 & {$[-0.061,0.071]$} & 0.144 & 0.885 \\
\hline & Primary intubation & 0.400 & {$[0.206,0.596]$} & 4.048 & $<0.001$ \\
\hline \multirow[t]{11}{*}{ Duration pre-hospital treatment } & VAT & -0.0001 & {$[-0.001,0.001]$} & -0.240 & 0.810 \\
\hline & Type of accident 2 & 0.643 & {$[0.288,1]$} & 3.566 & $<0.001$ \\
\hline & Type of accident 3 & 0.661 & {$[0.266,1.056]$} & 3.302 & 0.001 \\
\hline & Type of accident 4 & 0.371 & {$[-0.105,0.847]$} & 1.538 & 0.125 \\
\hline & Type of accident 5 & 0.883 & {$[0.457,1.31]$} & 4.080 & $<0.001$ \\
\hline & Type of accident 6 & 0.589 & {$[0.211,0.969]$} & 3.066 & 0.002 \\
\hline & Type of accident 7 & 0.608 & {$[0.002,1.215]$} & 1.977 & 0.049 \\
\hline & AIS thorax & -0.009 & {$[-0.071,0.052]$} & -0.300 & 0.764 \\
\hline & AIS abdomen & 0.020 & {$[-0.056,0.097]$} & 0.534 & 0.594 \\
\hline & AIS LOWER extremities & 0.001 & {$[-0.064,0.068]$} & 0.050 & 0.960 \\
\hline & Primary intubation & 0.391 & {$[0.196,0.588]$} & 3.935 & $<0.001$ \\
\hline \multirow[t]{11}{*}{ Duration pre-hospital treatment } & $\mathrm{SAT}+\mathrm{VAT}$ & 0.0001 & {$[0,0.001]$} & 0.626 & 0.531 \\
\hline & Type of accident 2 & 0.650 & {$[0.295,1.006]$} & 3.605 & $<0.001$ \\
\hline & Type of accident 3 & 0.673 & {$[0.278,1.069]$} & 3.356 & $<0.001$ \\
\hline & Type of accident 4 & 0.366 & {$[-0.11,0.842]$} & 1.517 & 0.130 \\
\hline & Type of accident 5 & 0.862 & {$[0.441,1.285]$} & 4.033 & $<0.001$ \\
\hline & Type of accident 6 & 0.582 & {$[0.204,0.961]$} & 3.034 & 0.002 \\
\hline & Type of accident 7 & 0.622 & {$[0.014,1.23]$} & 2.017 & 0.044 \\
\hline & AIS thorax & -0.010 & {$[-0.072,0.051]$} & -0.344 & 0.731 \\
\hline & AIS abdomen & 0.023 & {$[-0.053,0.1]$} & 0.611 & 0.541 \\
\hline & AIS lower extremities & 0.004 & {$[-0.062,0.07]$} & 0.120 & 0.904 \\
\hline & Primary intubation & 0.399 & {$[0.203,0.595]$} & 4.015 & $<0.001$ \\
\hline
\end{tabular}

The model includes following confounding factors: types of accident, AIS-Score of the body regions thorax, abdomen, lower extremities and primary intubation. Types of accident are: 1: rollover (reference) 2: passenger (car/truck) 3: motorcycle rider 4: cyclist 5: fall—height below $3 \mathrm{~m}$ 6: fall-height above $3 \mathrm{~m}$ 7: other 
Table 7 Multivariate linear regression for the impact of abdominal fat tissue parameters on the initial ED treatment, including the confounding variables AIS thorax/abdomen/lower extremities (re)intubation and shock

\begin{tabular}{|c|c|c|c|c|c|}
\hline Response & Independent variable & Beta coefficient & $95 \% \mathrm{CI}$ & $T$ value & $P$ value \\
\hline \multirow[t]{6}{*}{ Duration initial ED treatment } & SAD & -0.001 & {$[-0.014,0.011]$} & -0.280 & 0.779 \\
\hline & AIS thorax & -0.011 & {$[-0.049,0.027]$} & -0.591 & 0.555 \\
\hline & AIS abdomen & -0.017 & {$[-0.067,0.032]$} & -0.702 & 0.483 \\
\hline & AIS lower extremities & -0.0002 & {$[-0.038,0.038]$} & -0.012 & 0.990 \\
\hline & (Re)intubation & 0.136 & {$[-0.031,0.304]$} & 1.609 & 0.109 \\
\hline & Shock & 0.222 & {$[0.09,0.355]$} & 3.302 & 0.001 \\
\hline \multirow[t]{6}{*}{ Duration initial ED treatment } & SAT & 0.0003 & {$[0,0.001]$} & 1.271 & 0.205 \\
\hline & AIS thorax & -0.013 & {$[-0.051,0.025]$} & -0.685 & 0.494 \\
\hline & AIS abdomen & -0.013 & {$[-0.063,0.036]$} & -0.537 & 0.591 \\
\hline & AIS lower extremities & 0.0008 & {$[-0.037,0.038]$} & 0.043 & 0.965 \\
\hline & (Re)intubation & 0.137 & {$[-0.029,0.304]$} & 1.630 & 0.104 \\
\hline & Shock & 0.223 & {$[0.091,0.356]$} & 3.329 & 0.001 \\
\hline \multirow[t]{6}{*}{ Duration initial ED treatment } & VAT & -0.0003 & {$[-0.001,0]$} & -1.351 & 0.178 \\
\hline & AIS thorax & -0.011 & {$[-0.049,0.026]$} & -0.606 & 0.544 \\
\hline & AIS abdomen & -0.019 & {$[-0.069,0.029]$} & -0.803 & 0.422 \\
\hline & AIS lower extremities & -0.003 & {$[-0.041,0.035]$} & -0.162 & 0.871 \\
\hline & (Re)intubation & 0.146 & {$[-0.021,0.313]$} & 1.724 & 0.086 \\
\hline & Shock & 0.219 & {$[0.087,0.352]$} & 3.272 & 0.001 \\
\hline \multirow[t]{6}{*}{ Duration initial ED treatment } & $\mathrm{SAT}+\mathrm{VAT}$ & $1.382 \mathrm{e}-05$ & {$[-0.0003,0.0003]$} & 0.090 & 0.928 \\
\hline & AIS thorax & $-1.1943 \mathrm{e}-02$ & {$[-0.05,0.026]$} & -0.620 & 0.535 \\
\hline & AIS abdomen & $-1.681 \mathrm{e}-02$ & {$[-0.066,0.033]$} & -0.670 & 0.503 \\
\hline & AIS lower extremities & $4.643 e-04$ & {$[-0.037,0.038]$} & 0.024 & 0.980 \\
\hline & (Re)intubation & $1.359 \mathrm{e}-01$ & {$[-0.031,0.303]$} & 1.601 & 0.110 \\
\hline & Shock & $2.231 \mathrm{e}-01$ & {$[0.09,0.356]$} & 3.311 & 0.001 \\
\hline
\end{tabular}


Table 8 Multivariate logistic regression analysis of the relationship between shock on admission and fat/muscle tissue parameters, including the confounding variables age, AIS max/thorax/abdomen and duration of pre-hospital treatment

Table 9 Multivariate linear regression model with blood sugar as dependent variable, including the confounding variables age and duration of pre-hospital treatment

\begin{tabular}{|c|c|c|c|c|c|}
\hline Response & Independent variable & Odds ratio & $95 \% \mathrm{CI}$ & $z$ value & $P$ value \\
\hline \multirow[t]{6}{*}{ Shock } & SAD & 1.024 & {$[0.932,1.125]$} & 0.508 & 0.611 \\
\hline & Age & 0.986 & {$[0.964,1.008]$} & -1.186 & 0.235 \\
\hline & AIS max & 1.537 & {$[1.02,2.329]$} & 2.054 & 0.039 \\
\hline & AIS thorax & 1.128 & {$[0.876,1.465]$} & 0.931 & 0.351 \\
\hline & AIS abdomen & 1.541 & {$[1.164,2.071]$} & 2.965 & 0.003 \\
\hline & Duration pre-hospital treatment & 0.999 & {$[0.998,1.002]$} & -0.235 & 0.813 \\
\hline \multirow[t]{6}{*}{ Shock } & SAT & 1.000 & {$[0.997,1.004]$} & 0.256 & 0.798 \\
\hline & Age & 0.988 & {$[0.969,1.008]$} & -1.115 & 0.264 \\
\hline & AIS max & 1.533 & {$[1.018,2.324]$} & 2.043 & 0.041 \\
\hline & AIS thorax & 1.137 & {$[0.885,1.474]$} & 0.998 & 0.318 \\
\hline & AIS abdomen & 1.537 & {$[1.161,2.065]$} & 2.945 & 0.003 \\
\hline & Duration pre-hospital treatment & 0.999 & {$[0.998,1.002]$} & -0.186 & 0.852 \\
\hline \multirow[t]{6}{*}{ Shock } & VAT & 1.000 & {$[0.996,1.005]$} & 0.253 & 0.800 \\
\hline & Age & 0.987 & {$[0.963,1.011]$} & -1.009 & 0.313 \\
\hline & AIS max & 1.531 & {$[1.017,2.319]$} & 2.037 & 0.041 \\
\hline & AIS thorax & 1.138 & {$[0.886,1.474]$} & 1.003 & 0.315 \\
\hline & AIS abdomen & 1.536 & {$[1.161,2.062]$} & 2.946 & 0.003 \\
\hline & Duration pre-hospital treatment & 0.999 & {$[0.998,1.002]$} & -0.160 & 0.872 \\
\hline \multirow[t]{6}{*}{ Shock } & $\mathrm{SAT}+\mathrm{VAT}$ & 1.000 & {$[0.998,1.003]$} & 0.298 & 0.765 \\
\hline & Age & 0.988 & {$[0.966,1.009]$} & -1.091 & 0.275 \\
\hline & AIS max & 1.535 & {$[1.018,2.328]$} & 2.045 & 0.040 \\
\hline & AIS thorax & 1.136 & {$[0.884,1.472]$} & 0.990 & 0.322 \\
\hline & AIS abdomen & 1.539 & {$[1.162,2.068]$} & 2.950 & 0.003 \\
\hline & Duration pre-hospital treatment & 0.999 & {$[0.998,1.002]$} & -0.185 & 0.853 \\
\hline \multirow[t]{6}{*}{ Shock } & TMA & 0.999 & {$[0.991,1.008]$} & -0.098 & 0.921 \\
\hline & Age & 0.989 & {$[0.97,1.008]$} & -1.084 & 0.278 \\
\hline & AIS max & 1.525 & {$[1.014,2.305]$} & 2.026 & 0.042 \\
\hline & AIS thorax & 1.141 & {$[0.889,1.476]$} & 1.027 & 0.304 \\
\hline & AIS abdomen & 1.529 & {$[1.156,2.051]$} & 2.920 & 0.003 \\
\hline & Duration pre-hospital treatment & 0.999 & {$[0.998,1.002]$} & -0.145 & 0.884 \\
\hline
\end{tabular}

\begin{tabular}{llllll}
\hline Response & Independent variable & Beta coefficient & $95 \%$ CI & $T$ value & $P$ value \\
\hline Glucose & SAD & 2.479 & {$[0.813,4.147]$} & 2.932 & 0.003 \\
& Age & 0.343 & {$[-0.025,0.713]$} & 1.836 & 0.067 \\
& Duration pre-hospital treatment & 0.008 & {$[-0.028,0.044]$} & 0.444 & 0.657 \\
Glucose & SAT & 0.054 & {$[-0.003,0.112]$} & 1.868 & 0.063 \\
& Age & 0.530 & {$[0.192,0.869]$} & 3.091 & 0.002 \\
& Duration pre-hospital treatment & 0.011 & {$[-0.024,0.048]$} & 0.654 & 0.513 \\
Glucose & VAT & 0.134 & {$[0.053,0.217]$} & 3.234 & 0.001 \\
& Age & 0.232 & {$[-0.162,0.627]$} & 1.161 & 0.246 \\
& Duration pre-hospital treatment & 0.012 & {$[-0.023,0.048]$} & 0.696 & 0.487 \\
Glucose & SAT + VAT & 0.056 & {$[0.017,0.096]$} & 2.824 & 0.005 \\
& Age & 0.375 & {$[0.012,0.738]$} & 2.038 & 0.042 \\
& Duration pre-hospital treatment & 0.010 & {$[-0.025,0.046]$} & 0.602 & 0.548 \\
\hline
\end{tabular}


Table 10 Multivariate linear regression model with white blood cell count as dependent variable, including the confounding variables age and duration of pre-hospital treatment

\begin{tabular}{llcrrr}
\hline Response & Independent variable & Beta coefficient & $95 \%$ CI & $T$ value & $P$ value \\
\hline White blood cell count & SAD & 0.263 & {$[0.076,0.452]$} & 2.761 & 0.006 \\
& Age & -0.082 & {$[-0.124,-0.041]$} & -3.919 & $<0.001$ \\
& Duration pre-hospital treatment & -0.0002 & {$[-0.004,0.004]$} & -0.142 & 0.887 \\
White blood cell count & SAT & 0.010 & {$[0.004,0.017]$} & 3.293 & 0.001 \\
& Age & -0.068 & {$[-0.106,-0.031]$} & -3.628 & $<0.001$ \\
& Duration pre-hospital treatment & -0.0001 & {$[-0.004,0.004]$} & -0.062 & 0.950 \\
White blood cell count & VAT & 0.007 & {$[-0.002,0.017]$} & 1.644 & 0.101 \\
& Age & -0.076 & {$[-0.122,-0.032]$} & -3.352 & $<0.001$ \\
& Duration pre-hospital treatment & 0.0003 & {$[-0.004,0.004]$} & 0.148 & 0.882 \\
White blood cell count & SAT + VAT & $6.833 \mathrm{e}-03$ & {$[0.002,0.011]$} & 3.056 & 0.002 \\
& Age & $-8.286 \mathrm{e}-02$ & {$[-0.124,-0.042]$} & -4.015 & $<0.001$ \\
& Duration pre-hospital treatment & $-3.801 \mathrm{e}-05$ & {$[-0.004,0.004]$} & -0.019 \\
\hline
\end{tabular}

Table 11 Multivariate logistic regression analysis of the correlation between sepsis and fat/muscle tissue parameters, including the confounding variables age, AIS max, WBC and SAPS II score

\begin{tabular}{|c|c|c|c|c|c|}
\hline Response & Independent variable & Odds ratio & $95 \% \mathrm{CI}$ & $z$ value & $P$ value \\
\hline \multirow[t]{5}{*}{ Sepsis } & SAD & 1.060 & {$[0.977,1.151]$} & 1.400 & 0.161 \\
\hline & Age & 0.989 & {$[0.971,1.007]$} & -1.144 & 0.252 \\
\hline & AIS Max & 1.756 & {$[1.247,2.502]$} & 3.181 & 0.001 \\
\hline & WBC & 0.985 & {$[0.933,1.04]$} & -0.530 & 0.596 \\
\hline & SAPS II Score & 1.043 & {$[1.023,1.065]$} & 4.135 & $<0.001$ \\
\hline \multirow[t]{5}{*}{ Sepsis } & SAT & 0.998 & {$[0.996,1.002]$} & -0.698 & 0.485 \\
\hline & Age & 0.997 & {$[0.981,1.013]$} & -0.360 & 0.718 \\
\hline & AIS Max & 1.700 & {$[1.209,2.417]$} & 3.014 & 0.002 \\
\hline & WBC & 0.998 & {$[0.944,1.054]$} & -0.056 & 0.954 \\
\hline & SAPS II Score & 1.042 & {$[1.022,1.064]$} & 4.087 & $<0.001$ \\
\hline \multirow[t]{5}{*}{ Sepsis } & VAT & 1.001 & {$[0.997,1.005]$} & 0.681 & 0.496 \\
\hline & Age & 0.991 & {$[0.972,1.011]$} & -0.832 & 0.405 \\
\hline & AIS Max & 1.742 & {$[1.239,2.479]$} & 3.149 & 0.001 \\
\hline & WBC & 0.991 & {$[0.939,1.045]$} & -0.334 & 0.738 \\
\hline & SAPS II Score & 1.042 & {$[1.023,1.064]$} & 4.102 & $<0.001$ \\
\hline \multirow[t]{5}{*}{ Sepsis } & $\mathrm{SAT}+\mathrm{VAT}$ & 0.999 & {$[0.998,1.002]$} & -0.114 & 0.909 \\
\hline & Age & 0.996 & {$[0.978,1.014]$} & -0.426 & 0.670 \\
\hline & AIS Max & 1.721 & {$[1.223,2.449]$} & 3.076 & 0.002 \\
\hline & WBC & 0.993 & {$[0.94,1.049]$} & -0.219 & 0.826 \\
\hline & SAPS II Score & 1.042 & {$[1.022,1.064]$} & 4.065 & $<0.001$ \\
\hline \multirow[t]{5}{*}{ Sepsis } & TMA & 1.0069 & {$[0.999,1.016]$} & 1.651 & 0.098 \\
\hline & Age & 0.9971 & {$[0.981,1.013]$} & -0.348 & 0.728 \\
\hline & AIS Max & 1.6501 & {$[1.171,2.348]$} & 2.830 & 0.004 \\
\hline & WBC & 0.9863 & {$[0.934,1.04]$} & -0.506 & 0.613 \\
\hline & SAPS II Score & 1.0488 & {$[1.027,1.072]$} & 4.357 & $1.32 \mathrm{e}-05$ \\
\hline
\end{tabular}


Table 12 Multivariate linear regression analysis with duration of mechanical ventilation as dependent variable, including the confounding variables age, AIS head/thorax/face/neck and SAPS II score

\begin{tabular}{|c|c|c|c|c|c|}
\hline Response & Independent variable & Beta coefficient & $95 \% \mathrm{CI}$ & $T$ value & $P$ value \\
\hline \multirow[t]{7}{*}{ Duration mechanical ventilation } & SAD & 0.020 & {$[-0.04,0.081]$} & 0.667 & 0.506 \\
\hline & Age & 0.008 & {$[-0.005,0.022]$} & 1.230 & 0.221 \\
\hline & AIS head & 0.209 & {$[0.001,0.418]$} & 1.997 & 0.048 \\
\hline & AIS thorax & 0.182 & {$[0.024,0.34]$} & 2.287 & 0.024 \\
\hline & AIS face & -0.136 & {$[-0.441,0.167]$} & -0.894 & 0.373 \\
\hline & AIS neck & 0.302 & {$[-0.21,0.816]$} & 1.170 & 0.244 \\
\hline & SAPS II Score & 0.022 & {$[0.006,0.04]$} & 2.711 & 0.007 \\
\hline \multirow[t]{7}{*}{ Duration mechanical ventilation } & SAT & $-2.532 \mathrm{e}-05$ & {$[-0.002,0.002]$} & -0.024 & 0.981 \\
\hline & Age & $1.074 \mathrm{e}-02$ & {$[-0.002,0.023]$} & 1.685 & 0.095 \\
\hline & AIS head & $1.973 \mathrm{e}-01$ & {$[-0.01,0.405]$} & 1.886 & 0.062 \\
\hline & AIS thorax & $1.947 \mathrm{e}-01$ & {$[0.04,0.349]$} & 2.497 & 0.014 \\
\hline & AIS face & $-1.317 \mathrm{e}-01$ & {$[-0.436,0.172]$} & -0.859 & 0.392 \\
\hline & AIS neck & $3.097 \mathrm{e}-01$ & {$[-0.205,0.824]$} & 1.194 & 0.235 \\
\hline & SAPS II Score & $2.256 \mathrm{e}-02$ & {$[0.006,0.039]$} & 2.675 & 0.008 \\
\hline \multirow[t]{7}{*}{ Duration mechanical ventilation } & VAT & 0.001 & {$[-0.002,0.004]$} & 0.817 & 0.415 \\
\hline & Age & 0.007 & {$[-0.007,0.022]$} & 1.054 & 0.294 \\
\hline & AIS head & 0.208 & {$[0.002,0.415]$} & 2.004 & 0.047 \\
\hline & AIS thorax & 0.190 & {$[0.036,0.344]$} & 2.449 & 0.016 \\
\hline & AIS face & -0.148 & {$[-0.454,0.157]$} & -0.962 & 0.338 \\
\hline & AIS neck & 0.296 & {$[-0.216,0.81]$} & 1.147 & 0.254 \\
\hline & SAPS II Score & 0.023 & {$[0.006,0.04]$} & 2.736 & 0.007 \\
\hline \multirow[t]{7}{*}{ Duration mechanical ventilation } & TMA & 0.005 & {$[0,0.01]$} & 1.877 & 0.063 \\
\hline & Age & 0.013 & {$[0.001,0.025]$} & 2.070 & 0.040 \\
\hline & AIS head & 0.201 & {$[-0.004,0.407]$} & 1.947 & 0.054 \\
\hline & AIS thorax & 0.197 & {$[0.043,0.352]$} & 2.534 & 0.012 \\
\hline & AIS face & -0.097 & {$[-0.4,0.205]$} & -0.639 & 0.524 \\
\hline & AIS neck & 0.277 & {$[-0.231,0.786]$} & 1.082 & 0.281 \\
\hline & SAPS II Score & 0.025 & {$[0.008,0.043]$} & 2.903 & 0.004 \\
\hline
\end{tabular}

Table 13 Multivariate linear regression model with duration of ICU therapy as dependent variable

\begin{tabular}{llllrr}
\hline Response & Independent variable & Beta coefficient & $95 \%$ CI & $T$ value & $P$ value \\
\hline Duration ICU therapy & SAD & -0.007 & {$[-0.039,0.025]$} & -0.437 & 0.662 \\
& Age & 0.002 & {$[-0.004,0.01]$} & 0.809 & 0.419 \\
& AIS Max & 0.303 & {$[0.132,0.474]$} & 3.495 & $<0.001$ \\
& SAPS II Score & 0.03 & {$[0.02,0.04]$} & 6.143 & $<0.001$ \\
Duration ICU therapy & SAT & -0.0005 & {$[-0.002,0.001]$} & -0.925 & 0.355 \\
& Age & 0.002 & {$[-0.004,0.009]$} & 0.807 & 0.420 \\
& AIS Max & 0.297 & {$[0.128,0.467]$} & 3.458 & $<0.001$ \\
& SAPS II Score & 0.030 & {$[0.021,0.04]$} & 6.173 & $<0.001$ \\
Duration ICU therapy & VAT & -0.0005 & {$[-0.002,0.001]$} & -0.751 & 0.453 \\
& Age & 0.003 & {$[-0.004,0.012]$} & 0.986 & 0.325 \\
& AIS Max & 0.304 & {$[0.134,0.475]$} & 3.523 & $<0.001$ \\
& SAPS II Score & 0.030 & {$[0.02,0.04]$} & 6.143 & $<0.001$ \\
Duration ICU therapy & TMA & 0.0007 & {$[-0.002,0.004]$} & 0.436 & 0.663 \\
& Age & 0.0026 & {$[-0.004,0.009]$} & 0.769 & 0.442 \\
& AIS Max & 0.294 & {$[0.121,0.468]$} & 3.348 & $<0.001$ \\
& SAPS II Score & 0.030 & {$[0.02,0.04]$} & 5.948 & $<0.001$ \\
\hline
\end{tabular}


Table 14 Multivariate linear regression model with Glasgow Outcome Scale as dependent variable, including the confounding variables age, AIS max, SAPS II score and SOFA $\mathrm{CNS}>2$

\begin{tabular}{llllrr}
\hline Response & Independent variable & Beta coefficient & $95 \%$ CI & $t$ value & $P$ value \\
\hline Glasgow outcome scale & SAD & -0.007 & {$[-0.035,0.021]$} & -0.505 & 0.613 \\
& Age & 0.002 & {$[-0.004,0.009]$} & 0.763 & 0.446 \\
& AIS Max & -0.171 & {$[-0.329,-0.013]$} & -2.135 & 0.034 \\
& SAPS II Score & -0.016 & {$[-0.026,-0.008]$} & -3.598 & $<0.001$ \\
& SOFA CNS $>2$ & -0.444 & {$[-0.73,-0.159]$} & -3.073 & 0.002 \\
Glasgow outcome scale & SAT & $2.958 \mathrm{e}-05$ & {$[-0.001,0.001]$} & 0.061 & 0.951 \\
& Age & $1.808 \mathrm{e}-03$ & {$[-0.004,0.008]$} & 0.596 & 0.552 \\
& AIS Max & $-1.741 \mathrm{e}-01$ & {$[-0.332,-0.016]$} & -2.176 & 0.030 \\
& SAPS II-Score & $-1.662 \mathrm{e}-02$ & {$[-0.026,-0.007]$} & -3.571 & $<0.001$ \\
& SOFA CNS $>2$ & $-4.470 \mathrm{e}-01$ & {$[-0.733,-0.161]$} & -3.086 & 0.002 \\
Glasgow outcome scale & VAT & -0.0002 & {$[-0.002,0.001]$} & -0.320 & 0.749 \\
& Age & 0.002 & {$[-0.005,0.009]$} & 0.687 & 0.492 \\
& AIS Max & -0.172 & {$[-0.331,-0.015]$} & -2.157 & 0.032 \\
& SAPS II Score & -0.016 & {$[-0.026,-0.008]$} & -3.584 & $<0.001$ \\
& SOFA CNS $>2$ & -0.447 & {$[-0.733,-0.162]$} & -3.090 & 0.002 \\
TMA & 0.0002 & {$[-0.003,0.003]$} & 0.143 & 0.886 \\
Glasgow outcome scale & Age & 0.002 & {$[-0.004,0.008]$} & 0.718 & 0.473 \\
& AIS Max & -0.167 & {$[-0.328,-0.007]$} & -2.062 & 0.040 \\
& SAPS II Score & -0.017 & {$[-0.027,-0.008]$} & -3.617 & $<0.001$ \\
& SOFA CNS $>2$ & -0.456 & {$[-0.742,-0.171]$} & -3.155 & 0.001 \\
\hline
\end{tabular}

\section{References}

1. Liu T, Chen JJ, Bai XJ, Zheng GS, Gao W. The effect of obesity on outcomes in trauma patients: a meta-analysis. Injury. 2013;44(9):1145-52. https://doi.org/10.1016/j.injury.2012.10.038.

2. Lin G-M. The "obesity-mortality paradox"'in severely traumatic patients in intensive care unit. Injury. 2014;45(11):1799.

3. Werner BC, Rawles RB, Jobe JT, Chhabra AB, Freilich AM. Obesity is associated with increased postoperative complications after operative management of distal humerus fractures. J Shoulder Elbow Surg. 2015;24(10):1602-6. https://doi.org/10.1016/j. jse.2015.04.019.

4. Weinlein JC, Deaderick S, Murphy RF. Morbid obesity increases the risk for systemic complications in patients with femoral shaft fractures. J Orthop Trauma. 2015;29(3):e91-e9595. https://doi. org/10.1097/BOT.0000000000000167.

5. Cavo MJ, Fox JP, Markert R, Laughlin RT. Association between diabetes, obesity, and short-term outcomes among patients surgically treated for ankle fracture. J Bone Jt Surg Am. 2015;97(12):987-94. https://doi.org/10.2106/JBJS.N.00789.

6. Flodin L, Laurin A, Lokk J, Cederholm T, Hedstrom M. Increased 1 -year survival and discharge to independent living in overweight hip fracture patients: a prospective study of 843 patients. Acta Orthop. 2016;87(2):146-51. https://doi.org/10.3109/17453 674.2015.1125282.

7. Childs BR, Nahm NJ, Dolenc AJ, Vallier HA. Obesity is associated with more complications and longer hospital stays after orthopaedic trauma. J Orthop Trauma. 2015;29(11):504-9. https ://doi.org/10.1097/BOT.0000000000000324.

8. Deren ME, Babu J, Cohen EM, Machan J, Born CT, Hayda R. Increased mortality in elderly patients with sarcopenia and acetabular fractures. J Bone Jt Surg Am. 2017;99(3):200-6. https:// doi.org/10.2106/JBJS.16.00734.

9. Kaplan SJ, Pham TN, Arbabi S, Gross JA, Damodarasamy M, Bentov I, et al. Association of radiologic indicators of frailty with 1-year mortality in older trauma patients: opportunistic screening for sarcopenia and osteopenia. JAMA Surg. 2017;152(2):e164604. https://doi.org/10.1001/jamasurg.2016.4604.

10. Moisey LL, Mourtzakis M, Cotton BA, Premji T, Heyland DK, Wade CE, et al. Skeletal muscle predicts ventilator-free days, ICU-free days, and mortality in elderly ICU patients. Crit Care. 2013;17(5):R206. https://doi.org/10.1186/cc12901.

11. McCusker A, Khan M, Kulvatunyou N, Zeeshan M, Sakran JV, Hayek $\mathrm{H}$, et al. Sarcopenia defined by a computed tomography estimate of the psoas muscle area does not predict frailty in geriatric trauma patients. Am J Surg. 2018. https://doi.org/10.1016/j. amjsurg.2018.07.024.

12. Maurovich-Horvat P, Massaro J, Fox CS, Moselewski F, O'Donnell CJ, Hoffmann U. Comparison of anthropometric, area- and volume-based assessment of abdominal subcutaneous and visceral adipose tissue volumes using multi-detector computed tomography. Int J Obes (Lond). 2007;31(3):500-6. https://doi.org/10.1038/sj.ijo.0803454.

13. Hunter GR, Snyder SW, Kekes-Szabo T, Nicholson C, Berland L. Intra-abdominal adipose tissue values associated with risk of possessing elevated blood lipids and blood pressure. Obes Res. 1994;2(6):563-8.

14. Weijs PJ, Looijaard WG, Dekker IM, Stapel SN, Girbes AR, Oudemans-van Straaten HM, et al. Low skeletal muscle area is a risk factor for mortality in mechanically ventilated critically ill patients. Crit Care. 2014;18(2):R12. https://doi.org/10.1186/ cc13189.

15. Paris MT, Mourtzakis M, Day A, Leung R, Watharkar S, Kozar $\mathrm{R}$, et al. Validation of bedside ultrasound of muscle layer thickness of the quadriceps in the critically ill patient (VALIDUM Study). J Parenter Enteral Nutr. 2017;41(2):171-80. https://doi. org/10.1177/0148607116637852.

16. Wajchenberg BL. Subcutaneous and visceral adipose tissue: their relation to the metabolic syndrome. Endocr Rev. 2000;21(6):697-738. https://doi.org/10.1210/edrv.21.6.0415. 
17. Irlbeck T, Janitza S, Poros B, Golebiewski M, Frey L, Paprottka PM, et al. Quantification of adipose tissue and muscle mass based on computed tomography scans: comparison of eight planimetric and diametric techniques including a step-bystep guide. Eur Surg Res. 2018;59(1-2):23-34. https://doi. org/10.1159/000486173.

18. Paolini JB, Mancini J, Genestal M, Gonzalez H, McKay RE, Samii K et al. Predictive value of abdominal obesity vs. body mass index for determining risk of intensive care unit mortality. Crit Care Med. 2010;38(5):1308-14. doi:10.1097/ CCM.0b013e3181d8cd8b.

19. Williams MJ, Hunter GR, Kekes-Szabo T, Trueth MS, Snyder S, Berland L, et al. Intra-abdominal adipose tissue cut-points related to elevated cardiovascular risk in women. Int J Obes Relat Metab Disord. 1996;20(7):613-7.

20. Levy MM, Fink MP, Marshall JC, Abraham E, Angus D, Cook D, et al. 2001 SCCM/ESICM/ACCP/ATS/SIS international sepsis definitions conference. Intensive Care Med. 2003;29(4):530-8. https://doi.org/10.1007/s00134-003-1662-x.

21. Schoeneberg C, Kauther MD, Hussmann B, Keitel J, Schmitz $\mathrm{D}$, Lendemans $\mathrm{S}$. Gender-specific differences in severely injured patients between 2002 and 2011: data analysis with matched-pair analysis. Crit Care. 2013;17(6):R277. https://doi.org/10.1186/ cc13132.

22. Machann J, Thamer C, Schnoedt B, Stefan N, Stumvoll M, Haring $\mathrm{HU}$, et al. Age and gender related effects on adipose tissue compartments of subjects with increased risk for type 2 diabetes: a whole body MRI/MRS study. MAGMA. 2005;18(3):128-37. https://doi.org/10.1007/s10334-005-0104-x.

23. Demerath EW, Sun SS, Rogers N, Lee M, Reed D, Choh AC, et al. Anatomical patterning of visceral adipose tissue: race, sex, and age variation. Obesity (Silver Spring). 2007;15(12):2984-93. https://doi.org/10.1038/oby.2007.356.

24. Nutrition, Physical Activity and Obesity: Germany. WHO. 2013. https://www.euro.who.int/_data/assets/pdf_file/0011/243299/ Germany-WHO-Country-Profile.pdf?\%20ua=1. Accessed 12 Aug 2019.

25. Boulanger BR, Milzman D, Mitchell K, Rodriguez A. Body habitus as a predictor of injury pattern after blunt trauma. J Trauma. 1992;33(2):228-32.

26. Tagliaferri F, Compagnone C, Yoganandan N, Gennarelli TA. Traumatic brain injury after frontal crashes: relationship with body mass index. J Trauma. 2009;66(3):727-9. https://doi. org/10.1097/TA.0b013e31815edefd.
27. Andruszkow H, Veh J, Mommsen P, Zeckey C, Hildebrand F, Frink M. Impact of the body mass on complications and outcome in multiple trauma patients: what does the weight weigh? Mediators Inflamm. 2013;2013:345702. https://doi. org/10.1155/2013/345702.

28. Holmberg TJ, Bowman SM, Warner KJ, Vavilala MS, Bulger EM, Copass MK, et al. The association between obesity and difficult prehospital tracheal intubation. Anesth Analg. 2011;112(5):11328. https://doi.org/10.1213/ANE.0b013e31820effcc.

29. Gaither JB, Spaite DW, Stolz U, Ennis J, Mosier J, Sakles JJ. Prevalence of difficult airway predictors in cases of failed prehospital endotracheal intubation. J Emerg Med. 2014;47(3):294-300. https://doi.org/10.1016/j.jemermed.2014.04.021.

30. Rae L, Pham TN, Carrougher G, Honari S, Gibran NS, Arnoldo $\mathrm{BD}$, et al. Differences in resuscitation in morbidly obese burn patients may contribute to high mortality. J Burn Care Res. 2013;34(5):507-14. https://doi.org/10.1097/BCR.0b013e3182 a2a771.

31. Liu NT, Fenrich CA, Serio-Melvin ML, Peterson WC, Cancio LC, Salinas J. The impact of patient weight on burn resuscitation. J Trauma Acute Care Surg. 2017;83(1 Suppl 1):S112-S11919. https ://doi.org/10.1097/TA.0000000000001486.

32. Nelson J, Billeter AT, Seifert B, Neuhaus V, Trentz O, Hofer $\mathrm{CK}$, et al. Obese trauma patients are at increased risk of early hypovolemic shock: a retrospective cohort analysis of 1084 severely injured patients. Crit Care. 2012;16(3):R77. https://doi. org/10.1186/cc11334.

33. De Jong A, Deras P, Martinez O, Latry P, Jaber S, Capdevila X, et al. Relationship between obesity and massive transfusion needs in trauma patients, and validation of TASH score in obese population: a retrospective study on 910 trauma patients. PLoS ONE. 2016;11(3):e0152109. https://doi.org/10.1371/journal.pone.01521 09.

34. Richards JE, Morris BJ, Guillamondegui OD, Sweeney KR, Tressler MA, Obremskey WT, et al. The effect of body mass index on posttraumatic transfusion after pelvic trauma. Am Surg. 2015;81(3):239-44.

35. Chen SB, Lee YC, Ser KH, Chen JC, Chen SC, Hsieh HF, et al. Serum C-reactive protein and white blood cell count in morbidly obese surgical patients. Obes Surg. 2009;19(4):461-6. https://doi. org/10.1007/s11695-008-9619-3.

\section{Affiliations}

\section{Balázs Poros ${ }^{1} \cdot$ Thomas Irlbeck $^{1} \cdot$ Philipp Probst $^{2} \cdot$ Alexander Volkmann $^{2} \cdot$ Philipp Paprottka $^{3} \cdot$ Wolfgang Böcker $^{4}$. Michael Irlbeck ${ }^{1} \cdot$ Thomas Weig $^{1}$}

1 Department of Anaesthesiology, University Hospital, LMU Munich, Marchioninistr. 15, 81377 Munich, Germany

2 Institute for Medical Information Processing, Biometry, and Epidemiology, Faculty of Medicine, LMU Munich, Munich, Germany
3 Department of Interventional Radiology, Klinikum Rechts Der Isar, Technical University of Munich, Munich, Germany

4 Department of General, Trauma and Reconstructive Surgery, University Hospital, LMU Munich, Munich, Germany 